\title{
Demethylation of Somatic and Testis-Specific Histone H2A and H2B Genes in F9 Embryonal Carcinoma Cells
}

\author{
YOUNG-CHUL CHOI AND CHI-BOM CHAE* \\ Department of Biochemistry and Biophysics, University of North Carolina, \\ Chapel Hill, North Carolina 27599-7260
}

Received 28 December 1992/Returned for modification 6 April 1993/Accepted 23 June 1993

\begin{abstract}
In contrast to many other genes containing a CpG island, the testis-specific H2B (TH2B) histone gene exhibits tissue-specific methylation patterns in correlation with gene activity. Characterization of the methylation patterns within a 20-kb segment containing the TH2A and TH2B genes in comparison with that in a somatic histone cluster revealed that (i) the germ cell-specific unmethylated domain of the TH2A and TH2B genes is defined as a small region surrounding the CpG islands of the TH2A and TH2B genes and (ii) somatic histone genes are unmethylated in both liver and germ cells, like other genes containing CpG islands, whereas flanking sequences are methylated. Transfection of in vitro-methylated TH2B, somatic H2B, and mouse metallothionein I constructs into F9 embryonal carcinoma cells revealed that the CpG islands of the TH2A and TH2B genes were demethylated like those of the somatic H2A and H2B genes and the metallothionein I gene. The demethylation of those CpG islands became significantly inefficient at a high number of integrated copies and a high density of methylated CpG dinucleotides. In contrast, three sites in the somatic histone cluster, of which two sites are located in the long terminal repeat of an endogenous retrovirus-like sequence, were efficiently demethylated even at a high copy number and a high density of methylated CpG dinucleotides. These results suggest two possible mechanisms for demethylation in F9 cells and methylation of CpG islands of the TH2A and TH2B genes at the postblastula stage during embryogenesis.
\end{abstract}

DNA methylation is an important regulatory element involved in several cellular functions, such as regulation of gene activity $(4,7), X$-chromosome inactivation $(40,47)$, and parental imprinting $(51,52)$. The importance of DNA methylation in embryonic development is strongly emphasized by recent gene targeting experiments. Disruption of a DNA methyltransferase gene resulted in abnormal development and lethality of homozygous embryos at mid-gestation (34). Although the mechanism underlying the establishment of methylation patterns is not clearly understood, there are a large number of reports on the tissue-specific methylation patterns of unique and repetitive sequences. In mammals, approximately $70 \%$ of all $\mathrm{CpG}$ dinucleotides (CpGs) are methylated at the $5^{\prime}$ position of the cytosine residue. The remaining unmethylated $\mathrm{CpGs}$ are found at a region called a "CpG island," which is associated with the $5^{\prime}$ ends of all housekeeping genes and some tissue-specific genes $(5,14)$. The $\mathrm{CpG}$ islands are $\mathrm{CpG}$ rich and $\mathrm{C}+\mathrm{G}$ rich, and they are unmethylated in all tissues, except those on inactive $X$ chromosomes $(35,46)$ and in in vitro-cultured cell lines (1). Tissue-specific genes are normally heavily methylated in nonexpressing tissues, thus exhibiting an inverse relationship between DNA methylation and gene activity. Taken together, the simplest picture of the global methylation pattern in adult somatic tissues appears to be the unmethylated $\mathrm{CpG}$ islands flanked by methylated and $\mathrm{CpG}$-depleted bulk DNA.

In contrast to the well-established methylation patterns of the genes in differentiated cell types, much less is known about the changes in methylation patterns during early embryogenesis and gametogenesis, partly because of the difficulties in obtaining sufficient amounts of early embryo and highly purified germ cells for methylation analysis. By

\footnotetext{
* Corresponding author.
}

monitoring the changes in overall methylation patterns during embryogenesis, Monk et al. (42) have shown that there was a gradual loss of methylation of parental genomic DNA during preimplantation development, resulting in striking unmethylation of blastocyst DNA. The extensive de novo methylation at the postblastula stage led to the high level of DNA methylation in adult somatic tissues. The gradual demethylation from the eight-cell stage through the blastocyst stage has also been reported for the repetitive sequence L1 and intracisternal A-particle elements $(23,49)$. Recently, by using a sensitive polymerase chain reaction-based assay $(54,56)$, Kafri et al. (25) have assayed the methylation status of sites in the $\mathrm{CpG}$ islands and non-CpG islands of both tissue-specific genes and housekeeping genes. Their results, consistent with the overall changes in methylation patterns, have shown that all of the sites assayed were unmethylated at the 16-cell and blastocyst stages and that non-CpG islands were remodified in 6.5-day embryos, whereas CpG island sites were unmethylated at all stages.

Although these results provide valuable information on the developmental changes in the methylation patterns, the mechanism underlying the formation of methylation patterns is not known. The main steps to be understood may be the demethylation of non-CpG island sequences in early embryo and fetal germ cells and the protection of $\mathrm{CpG}$ islands from de novo methylation at the postblastula stage. As far as the mechanism for the protection of $\mathrm{CpG}$ islands from de novo methylation is concerned, it has been shown that in vitromethylated CpG island DNAs were demethylated by a so-called "island demethylation system" through an active enzymatic mechanism when introduced into embryonic cell lines (13). The demethylation was specific for $\mathrm{CpG}$ islands, since the non-CpG island sites in the flanking sequences of the adenine phosphoribosyltransferase (APRT) gene and insulin genes were not demethylated. It was suggested that a protein factor(s) of this nature may be involved in the 
protection of $\mathrm{CpG}$ islands from de novo methylation in the early embryo stage.

Previously, we have shown that the $\mathrm{CpG}$ islands of the testis-specific H2A (TH2A) and TH2B genes were methylated in nonexpressing somatic tissues (10). On the basis of data on the developmental changes in methylation patterns, one possible explanation for the exceptional methylation of the CpG islands of the TH2A and TH2B genes was that the TH2A and TH2B genes are not protected from de novo methylation in 6.5-day embryos because of the lack of the putative signal necessary for recognition by an island demethylation system (13). In this study, we tested the possibility by transfecting in vitro-methylated TH2A and TH2B genes into F9 embryonal carcinoma cells. At a low copy number, the $\mathrm{CpG}$ islands of the TH2A and TH2B genes were demethylated like those of the somatic $\mathrm{H} 2 \mathrm{~A}(\mathrm{sH} 2 \mathrm{~A}), \mathrm{sH} 2 \mathrm{~B}$, and mouse metallothionein I (MT-I) genes, whereas most of the integrated copies did not undergo demethylation at a high copy number, suggesting that the saturable factor(s) is involved in the demethylation of those $\mathrm{CpG}$ islands. Efficient demethylation of the $\mathrm{CpG}$ islands at a low number of integrated copies was greatly inhibited by the increased density of methylated CpG dinucleotides (mCpGs). Interestingly, three sites in the in vitro-methylated $\mathrm{sH} 2 \mathrm{~B}$ construct and an HpaII site in simian virus 40 (SV40) sequences were efficiently demethylated, even at a high number of integrated copies, as well as a high density of mCpGs. In all cases, de novo methylation of the unmethylated constructs in F9 cells was not apparent. These findings indicate that two different mechanisms are involved in demethylation in F9 cells. Also, they suggest that de novo methylation of the TH2A and TH2B genes plays a dominant role over demethylation in the exceptional methylation of the CpG islands of TH2A and TH2B genes in somatic tissues at the postblastula stage during embryogenesis.

\section{MATERIALS AND METHODS}

Cloning and DNA constructs. The recombinant phage clone containing the TH2B ( $\lambda$ TH101) or sH2B ( $\lambda$ SH-1) gene has been previously isolated from a rat genomic HaeIII library established in Charon 4A (a gift from T. D. Sargent) (26). To isolate the flanking sequences $3^{\prime}$ to the TH2B gene, we screened a rat genomic library constructed in the $\lambda$ GEM11 vector (Promega Co.) with a radiolabeled HinfI$M s p I$ intergenic DNA fragment as a probe. The $12.6-\mathrm{kb} X b a \mathrm{I}$ fragment containing $3.2 \mathrm{~kb}$ of $5^{\prime}$ sequences, $8.2 \mathrm{~kb}$ of $3^{\prime}$ sequences, and the coding sequences of the TH2A and TH2B genes was excised from the positive clone ( $\lambda$ TH103) and subcloned into pSP72 (Promega Co.) to give plasmid p10-3. Plasmid p10-1 was constructed by cloning an 11.1-kb EcoRI fragment of the $\lambda$ TH101 clone into plasmid pBluescribe (Vector Cloning Systems).

The following constructs were used in the transfection experiments. TH-S: to avoid possible biased selection against cells expressing the TH2B gene at a higher level, because of the possible toxic effect of the TH2B histone protein on somatic cells, frameshift mutations were introduced into the coding sequences of both the TH2A and TH2B genes. Plasmid pTHAB (10) was partially digested with $X m a I$, filled in with Klenow, and ligated to insert four bases (CCGG) in the coding sequences of the TH2B gene. Of two XmaI sites present in the coding sequences of the TH2B gene, the mutation introduced into the XmaI site which is close to the initiation codon was identified by restriction analysis. The mutation in the body of the TH2A gene was introduced into the resulting plasmid by cutting with EagI, filling in with Klenow, and ligating the blunted ends. The resulting plasmid, TH-S (4.5 kb), carries frameshift mutations in both the TH2A and TH2B genes. TH-M: to introduce those mutations into plasmid p10-3, an SmaI-NcoI fragment carrying both mutations was isolated from plasmid TH-S and used to replace the corresponding fragment in p10-3. SH-M: $\lambda$ SH-1 DNA was partially digested with EcoRI, and an about 9.5-kb EcoRI DNA fragment was inserted into the EcoRI site of pSP72. SH-S: a 1.5-kb EcoRI-ScaI fragment of SH-M containing the $\mathrm{sH} 2 \mathrm{~A}$ and sH2B genes was inserted into the EcoRI-SmaI site of pUC19. Plasmid pJYMMT(L), comprising an approximately 4-kb EcoRI fragment of the mouse MT-I gene, was generously provided by D. H. Hamer (20). Nucleotide sequences were determined by the dideoxynucleotide chain termination method (50) with a Sequenase kit (U.S. Biochemical) in accordance with the manufacturer's protocol. For sequencing, DNA was either subcloned in pUC19 or a series of oligonucleotides was synthesized and used as primers.

Mapping of the locations of histone genes. To identify the locations of histone genes, recombinant clones $\lambda$ TH101- $\lambda$ TH103 and $\lambda$ SH-1 were digested with EcoRI-HindIII and EcoRI, respectively. Restriction digests were electrophoresed on a $1 \%$ agarose gel, transferred onto a nylon filter, and hybridized with ${ }^{32} \mathrm{P}$-labeled histone-specific probes. Histone $\mathrm{H} 3-$ and H4-specific probes were isolated from plasmids pSp3-1 and pGC42 containing the sea urchin $\mathrm{H} 3$ and $\mathrm{H} 4$ genes (a gift from L. Kedes), respectively. The composition of the hybridization buffer was as previously described (10), except that salmon sperm DNA was replaced by Escherichia coli DNA $(200 \mu \mathrm{g} / \mathrm{ml})$. The precise position of the $\mathrm{H} 3$ histone gene in the $\lambda \mathrm{SH}-1$ clone was further determined by sequencing analysis.

Mapping of the locations of repetitive sequences. To identify the locations of repetitive sequences, we used two different approaches. EcoRI-HindIII digests of $\lambda$ TH101- $\lambda$ TH103 and EcoRI digests of $\lambda \mathrm{SH}-1$ clones on a nylon filter were hybridized with ${ }^{32} \mathrm{P}$-labeled total rat genomic DNA. Under the hybridization conditions used in our experiments, only restriction fragments containing abundant repetitive sequences can be detected. Since this method is insensitive to repetitive sequences with a low copy number, we used a second method to map the boundaries of repetitive sequences more accurately. Various nonoverlapping restriction fragments isolated from subclones p10-1, p10-3, and SH-M were ${ }^{32} \mathrm{P}$ labeled and used as probes to hybridize to EcoRI-digested total rat genomic DNA in Southern blot analysis. The presence of repetitive sequences in the probe fragments could be identified by multiple bands or smears, depending on the repetition frequency.

DNA isolation and methylation analysis. High-molecularweight genomic DNA was isolated from the nuclei of rat tissues and cultured cells as previously described (10). To determine the methylation status of cytosine residues, restriction enzyme isoschizomers MspI and HpaII were used. The MspI enzyme can cut CCGG sequences irrespective of DNA methylation, but $H p a$ II cannot cut $\mathrm{C}^{\mathrm{m}} \mathrm{CGG}$ sequences. Genomic DNA was first digested with appropriate methylation-insensitive restriction enzymes and subsequently with either restriction enzyme MspI or $\mathrm{HpaII}(10 \mathrm{U} / \mu \mathrm{g})$ for $16 \mathrm{~h}$ at $37^{\circ} \mathrm{C}$. The samples were then extracted with phenol-chloroform, precipitated with ethanol, and solubilized in TE (10 mM Tris-HCl [pH 7.4], 1 mM EDTA). Electrophoresis, Southern blot transfer, and hybridization with various probes were carried out as previously described (10). 
In vitro methylation. The constructs were methylated at every CpG dinucleotide by using methyltransferase SssI (2 $\mathrm{U} / \mu \mathrm{g}$ of DNA; New England BioLabs) or at CCGG and GCGC sequences with bacterial methyltransferases $\mathrm{HpaII}$

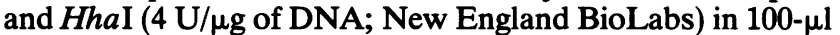
reaction mixtures containing $10 \mu \mathrm{g}$ of DNA and buffer (SssI, $50 \mathrm{mM} \mathrm{NaCl}-10 \mathrm{mM}$ Tris-HCl [pH 7.9]-10 mM MgCl $2-160$ $\mu \mathrm{M} S$-adenosylmethionine-1 $\mathrm{mM}$ dithiothreitol; HpaIIHhal, $50 \mathrm{mM}$ Tris-HCl [pH 7.5]-10 mM EDTA-5 mM $\beta$-mercaptoethanol-160 $\mu \mathrm{M} S$-adenosylmethionine). The reaction mixture was incubated at $37^{\circ} \mathrm{C}$ for $20 \mathrm{~h}$. The DNA was purified by extraction with phenol and chloroform, followed by ethanol precipitation. Mock methylations were carried out under the same conditions except that $S$-adenosylmethionine was omitted from the reaction mixture. Complete methylation was checked by restriction analysis.

Cell culture and transfection. Mouse F9 teratocarcinoma and $\mathrm{L}-\mathrm{M}\left(\mathrm{tk}^{-}\right)$(ATCC CCL1.3) cells were maintained in Dulbecco modified Eagle medium supplemented with $10 \%$ (vol/vol) heat-inactivated fetal bovine serum and penicillin $(500 \mathrm{U} / \mathrm{ml})$-streptomycin sulfate $(100 \mu \mathrm{g} / \mathrm{ml})$ in a $5 \% \mathrm{CO}_{2}$ atmosphere. To isolate stable transformants, cells on 60mm-diameter plates were transfected with $1 \mu \mathrm{g}$ of test DNA, $1 \mu \mathrm{g}$ of carrier salmon sperm DNA, and $0.2 \mu \mathrm{g}$ of pMC neopolyA (Stratagene) by using Transfectam Reagent (Promega Co.) in accordance with the manufacturer's instruction. To obtain stable transformants containing a low number of integrated copies, $0.2 \mu \mathrm{g}$ of test DNA, $1.8 \mu \mathrm{g}$ of the carrier, and $0.05 \mu \mathrm{g}$ of pMCneopolyA were transfected into F9 cells. After incubation at $37^{\circ} \mathrm{C}$ for $16 \mathrm{~h}$, fresh medium was added. After $48 \mathrm{~h}$, the medium was changed to G418containing medium $(250 \mu \mathrm{g} / \mathrm{ml})$. After 2 to 3 weeks, G418resistant colonies were pooled and expanded to mass culture. For stable transfection in the differentiated cell type, mouse $\mathrm{L}-\mathrm{M}\left(\mathrm{tk}^{-}\right)$cells were transfected with $1 \mu \mathrm{g}$ of test DNA, $1 \mu \mathrm{g}$ of the carrier, and $0.2 \mu \mathrm{g}$ of RSVneo. G418resistant cells were selected in a medium containing $250 \mu \mathrm{g}$ of $\mathrm{G} 418$ per $\mathrm{ml}$ for 3 to 4 weeks before being allowed to grow in mass culture for further analysis. To examine expression of the TH2B gene, the TH-M construct was stably transfected into mouse embryonic fibroblast $\mathrm{C} 3 \mathrm{H} 10 \mathrm{~T} 1 / 2$ cells as described previously (10). S-phase cells were harvested at 4 (C3H 10T1/2) or 2 (F9) h after release from the aphidicolin block. Non-S-phase cells were harvested after $20 \mathrm{~h}$ of incubation with aphidicolin. RNA was isolated from S- and non-S-phase cells and subjected to Northern (RNA) blot analysis as previously described (10). The probe specific for the TH2B transcript was a 217-bp EcoRI-XmnI fragment, and the probe specific for the H2B coding region was a 394-bp HincII-SacI fragment isolated from the SH-S plasmid. Also, plasmids TH2B-CAT, OM-3 (octamer mutant of TH2B-CAT), and pSV2-CAT were transiently transfected into $\mathrm{F} 9$ or $\mathrm{C} 3 \mathrm{H} 10 \mathrm{~T} 1 / 2$ cells by using pRSV $\beta$-gal as a cotransfection control as described previously (24). To assay chloramphenicol acetyltransferase (CAT) activity in the S phase, cells were harvested at 4 (F9) or 7 (C3H 10T1/2) h after release from the aphidicolin block. Non-S-phase cells were incubated in the presence of aphidicolin for $24 \mathrm{~h}$. CAT assay of samples from S- and non-S-phase cells were done as described previously $(15,16)$.

\section{RESULTS}

Genomic organization of histone genes. Since our previous study showed that DNA methylation is associated with transcriptional regulation of the TH2B gene (10), we ex-

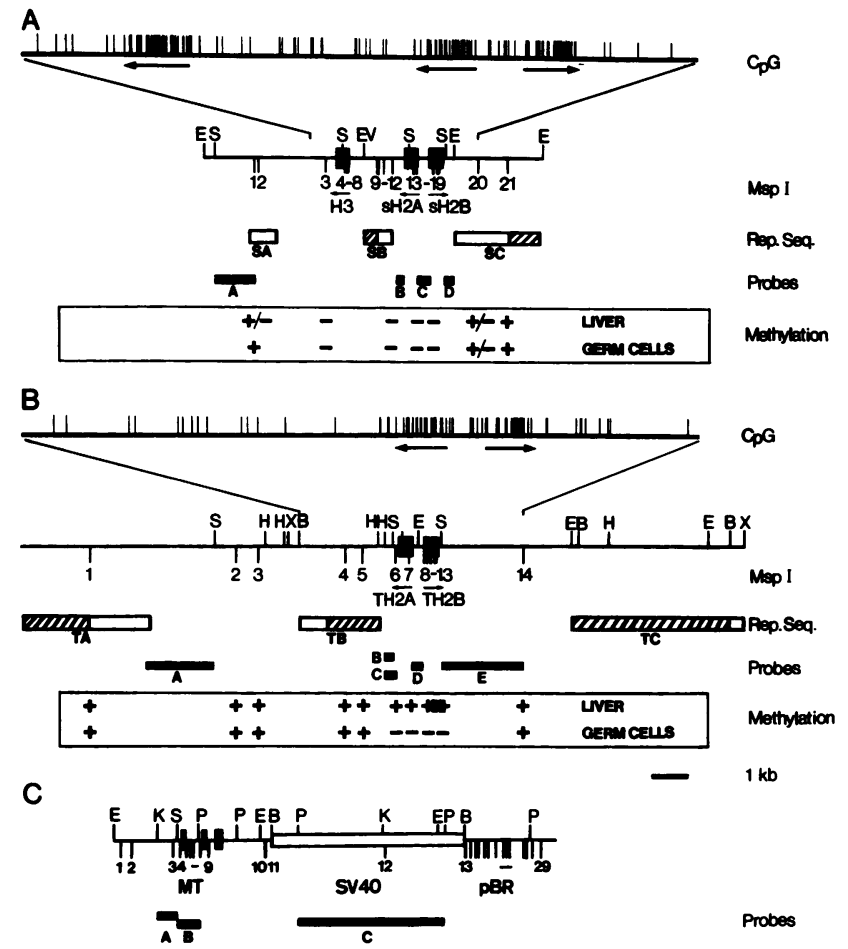

FIG. 1. Genomic organization of somatic and testis-specific histone genes. $\mathrm{sH} 2 \mathrm{~A}, \mathrm{sH} 2 \mathrm{~B}$, and $\mathrm{sH} 3$ histone genes in a 9.5-kb segment of the $\lambda$ SH-1 clone (A) and TH2A and TH2B histone genes in a 20-kb segment spanning overlapping clones $\lambda$ TH101 and $\lambda$ TH103 (B). The positions and direction of transcription of histone genes are indicated by the closed boxes and arrows below the boxes, respectively. Vertical lines below the bar indicate MspI sites and are numbered from $5^{\prime}$ to $3^{\prime}$. The expanded region shows the distribution of $\mathrm{CpG}$ dinucleotides over a 5.5 -kb sequenced segment containing the TH2A and TH2B or somatic histone genes. As in many other genes (31), CpG islands are markers for histone genes, too; the bodies of histone genes are CpG rich, whereas flanking sequences are CpG depleted. The restriction fragments containing highly repetitive sequences (Rep. Seq.), as detected by using ${ }^{32} \mathrm{P}$-labeled total rat genomic DNA as a probe, are indicated by the hatched boxes. The fragments comprising repetitive sequences with a low reiteration number are indicated by open boxes. Closed boxes represent the fragments used as probes to evaluate the methylation status of MspI sites. The methylation status of MspI sites is indicated as follows: + , heavily methylated; $+/-$, partially methylated; -, unmethylated. (C) Map of plasmid t 25 containing mouse MT-I gene and SV40 DNAs. Three exons of the mouse MT-I gene in an approximately 4-kb EcoRI fragment are indicated by closed boxes. SV40 is indicated by an open box. Probes for somatic histones: A, SacI-MspI (1.13 kb); B, BstEII-ScaI (0.18 kb); C, SspI-HincII $(0.27 \mathrm{~kb})$; D, SacI-EcoRI $(0.2 \mathrm{~kb})$. Probes for the TH2A and TH2B genes: A, BglII-SacI (1.85 kb); B, HindIII-SacI (0.28 kb); C, HindIII-PvuII (0.41 kb); D, HinfI-MspI (0.31 kb); E, SacI-MspI $(2.35 \mathrm{~kb})$. Probes for t25: A, KpnI-SacI $(0.45 \mathrm{~kb})$; B, SacI-PstI $(0.64$ kb); C, PstI (4.03 kb). Restriction sites: B, BamHI; E, EcoRI; EV, EcoRV; H, HindIII; K, KpnI; P, PstI; S, SacI; X, XbaI. Not all SacI sites are shown.

tended our methylation analysis to the flanking sequences to determine the germ cell-specific unmethylated domain of the TH2B gene. We first isolated recombinant lambda clones containing the TH2B gene, as well as the sH2B gene as a control. Clones $\lambda$ TH101 and $\lambda$ TH103 are two overlapping clones which together span a 20 -kb segment surrounding a TH2A-TH2B pair (Fig. 1B), and clone $\lambda$ SH-1 contains the 


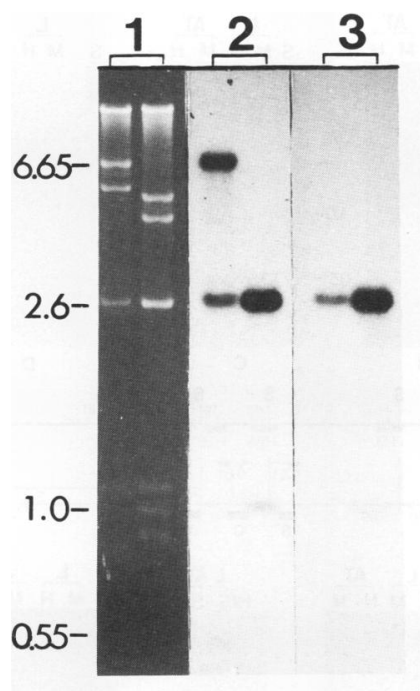

TH101/ TH103

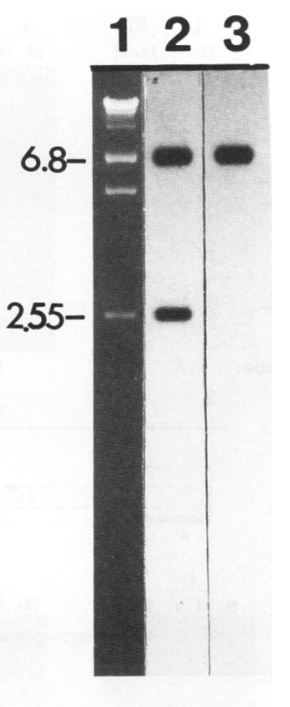

$\mathrm{SH}-1$
FIG. 2. Southern blot analysis of recombinant $\lambda$ clones with ${ }^{32} \mathrm{P}$-labeled total rat genomic DNA. EcoRI-HindIII digests of clones $\lambda$ TH101 and $\lambda$ TH103 or EcoRI digest of clone $\lambda$ SH-1 were fractionated on a $1 \%$ agarose gel, transferred to a Nytran membrane (Schleicher \& Schuell), and hybridized with ${ }^{32} \mathrm{P}$-labeled total rat genomic DNA in a hybridization solution containing $200 \mu \mathrm{g}$ of sonicated and denatured $E$. coli DNA (lane 2) or salmon sperm DNA (lane 3 ) per $\mathrm{ml}$. The disappearance of hybridization bands $(6.65-\mathrm{kb}$ band in $\lambda$ TH101 and 2.55-kb band in $\lambda$ SH-1) when hybridized in a solution containing salmon sperm DNA indicates that the sequences homologous to the repetitive sequences in the corresponding fragments are present in salmon sperm DNA. Lane 1, ethidium bromidestained gel patterns of $\lambda$ clones cleaved with EcoRI-HindIII $(\lambda$ TH101 and $\lambda$ TH103) and EcoRI ( $\lambda$ SH-1). Molecular sizes (in kilobases) of hybridization bands are indicated to the left of each panel.

sH2A and sH2B genes in an approximately 14-kb insert (Fig. $1 \mathrm{~A} ; 9.5$-kb segment of $14-\mathrm{kb}$ insert). Since histone genes in higher eukaryotes are often present as a dispersed cluster, the cloned DNAs were analyzed for the presence of histone genes other than the H2A and H2B genes by Southern blot analysis with the sea urchin histone genes as a probe. The results showed that an $\mathrm{H} 3$ gene is located downstream of the sH2A gene in the $\lambda$ SH-1 clone (Fig. 1A) and an $\mathrm{H} 4$ gene was found in the 4.5-kb EcoRI fragment located $3^{\prime}$ of the 2.55-kb $E c o$ RI fragment in the $\lambda$ SH-1 clone (data not shown), whereas these genes were not identified in a $20-\mathrm{kb}$ segment containing the TH2A and TH2B genes.

Also, it was necessary to determine the positions of repetitive sequences because a large fraction of genomic DNA in eukaryotes contains repetitive sequences which cannot be used as probes for methylation analysis. To identify restriction fragments suitable for use as probes for methylation analysis, we used two different approaches. The first method, which involves hybridization of ${ }^{32} \mathrm{P}$-labeled total rat genomic DNA with restriction fragments of cloned DNA on Southern filters, detects highly repeated sequences, thus identifying abundant repetitive sequences or the more repeated core sequences of the given repetitive sequences. Figure 2 shows the results of Southern blot analysis, and Fig. 1 gives the map of restriction fragments which bound detectable amounts of the ${ }^{32} \mathrm{P}$-labeled rat genomic DNA probe. The locations of repetitive sequences within the detected restriction fragments were more precisely determined by using isolated restriction fragments as probes to hybridize with EcoRI-digested total rat genomic DNA (data not shown). By using two complementary methods, we identified at least three repetitive sequences which are present in a 20-kb segment surrounding the TH2A and TH2B genes, as well as a 14-kb segment containing a somatic histone cluster (Fig. 1 and 2). Sequence analysis of the approximately 5.5-kb segment containing the TH2A and TH2B or the sH2A and sH2B genes revealed sequences in the TB, SB, and SA regions (see Fig. 1) that share extensive homology with the consensus ID $(9,39)$ and $\mathrm{B} 2(9,27)$ regions and the long terminal repeat (LTR)-like sequences called RAL elements $(44,59)$ (Fig. 3), respectively.

Methylation patterns of histone genes in rat tissues. To determine the long-range methylation patterns, methylationsensitive enzyme HpaII and its isoschizomer MspI were used. Both enzymes recognize CCGG, but HpaII activity is inhibited when the internal cytosine is methylated. Because of the close proximity of various repetitive sequences to histone genes, the methylation analysis required numerous genomic blots with relatively small DNA fragments as probes. Figure 4B shows that all of the sites examined within a 20-kb segment surrounding the TH2B gene are methylated in liver tissue. In adult testis tissue, the germ cell-specific unmethylation was detected at MspI sites M6 (located 0.13 kb downstream of the TH2A gene; probe C), M7 (in the body of the TH2A gene; 10), M8 (10), and M13 (in the body of the TH2B gene; probe D), whereas the sites outside M6 and M13 are methylated in both liver and germ cells, as indicated by the 5.01-kb (probe B) and 3.7-kb (probe E) bands in the HpaII lanes. The same germ cell-specific methylation patterns were detected in sperm (data not shown). Although there are gaps between the sites that limit the boundaries because of the absence of testable enzyme sites, these results allowed us to define the germ cell-specific unmethylated domain of the TH2A and TH2B genes as a relatively small region surrounding the $\mathrm{CpG}$ islands of the TH2A and TH2B genes (Fig. 1B).

In contrast to the TH2A and TH2B genes, all of the sites tested, except MspI sites 1 and/or 2, within a 9.5-kb segment containing the $\mathrm{sH} 2 \mathrm{~A}$ and $\mathrm{sH} 2 \mathrm{~B}$ genes exhibited the same methylation patterns in both somatic and germ cells (Fig. 1A). While MspI sites 3 (2.93-kb band in HpaII lanes; probe A), 12 (probe B), 15, and 16 (probe C), which are associated with the CpG islands of somatic histone genes, are unmethylated, site 21 in repetitive SC sequences (probe $D$ ) is methylated in both liver and germ cells (Fig. 4A). The partial methylation of MspI site 20, which is indicated by the weak 0.8-kb band in the HpaII lanes, may be related to its location close to the CpG island of the sH2B gene (Fig. 4A, probe D). Site M1, located in the LTR of RAL sequences, is completely methylated in germ cells but only partially methylated in liver cells (Fig. 4A, probe A). These patterns are consistent with the general picture of global methylation patterns in the eukaryotic genome, showing the unmethylated $\mathrm{CpG}$ island flanked by methylated bulk DNA. The methylation of the CpG islands of the TH2A and TH2B genes provides a rare exception to the methylation-free $\mathrm{CpG}$ islands.

Efiect of copy number on demethylation in F9 cells. The well-defined and relatively small unmethylated domains of histone genes flanked by methylated repetitive sequences, as well as the exceptional methylation of $\mathrm{CpG}$ islands in the TH2A and TH2B genes, in contrast to those of the sH2A and sH2B genes, despite more than $80 \%$ sequence homology in 


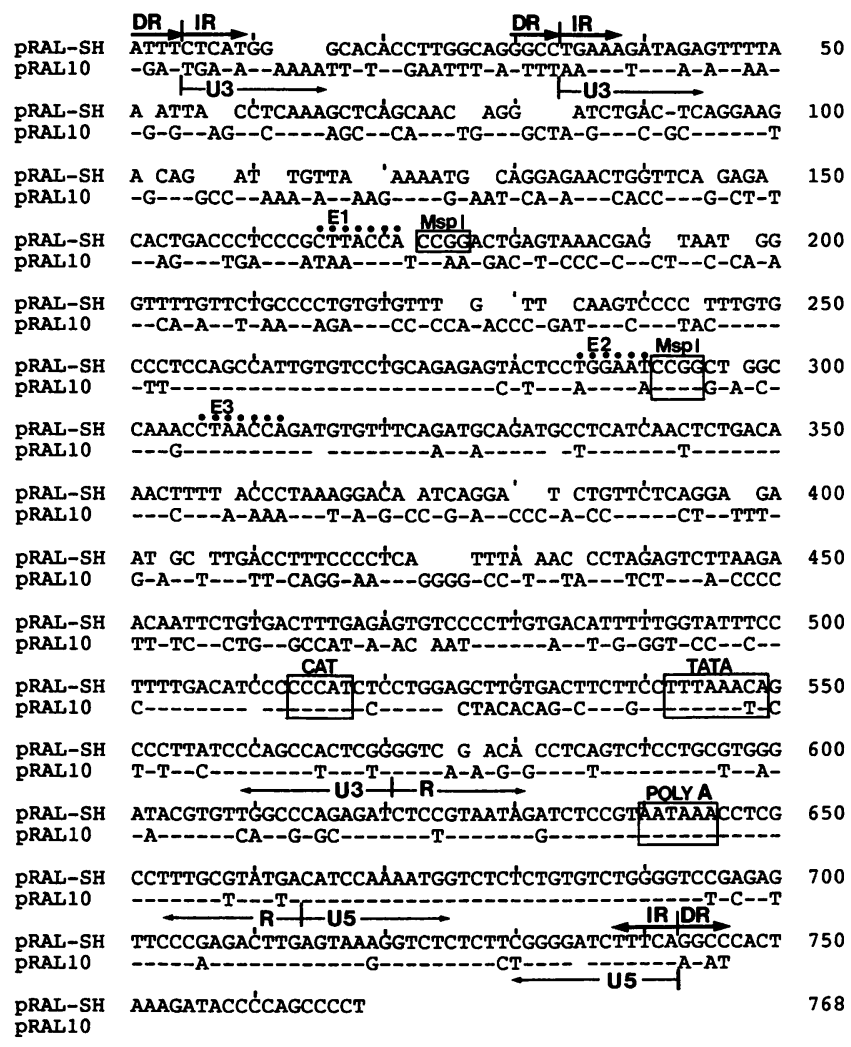

FIG. 3. Sequence comparison of the LTR-like RAL elements in pSH-M and pRAL10. The LTR-like RAL element in pSH-M (pRAL-SH) is aligned with that in pRAL10 (59). Bars represent identical nucleotides, and spacers are gaps introduced for optimal alignment. Letters show where the pRAL10 sequence differs from the pRAL-SH sequence. The U3, U5, and R regions are indicated. The $5^{\prime}$ boundary of the $U 3$ region was tentatively determined by the presence of the inverted repeat (IR) 5' TGAAA-TTTCA 3', which is immediately flanked by the 4-bp direct repeat (DR) GGCC. The direct repeat flanking the entire LTR may indicate the duplication of the target sequences generated on insertion (45). The CAT, TATA, and polyadenylation signals are boxed. Two MspI sites that were efficiently demethylated in F9 cells (see Fig. 7 and 8) are also boxed. The 5' MspI site corresponds to MspI site 1 in Fig. 1A. The E1, E2, and E3 sequences homologous to the enhancer core sequences (GTGG[T/A][T/A][T/A]) (61) are indicated by dots. The presence of E1, E2, and E3 sequences immediately adjacent to two MspI sites suggests possible involvement of the passive mechanism in efficient demethylation at those sites. The competitive binding of protein factors to their closely located target sequences may interfere with methyltransferase activity on the hemimethylated intermediate during DNA replication.

the coding sequences, provide a good model system to examine the signal involved in the formation of methylation patterns during embryogenesis. For a systematic analysis, we examined the effects of the number of integrated copies, the flanking sequences, and the density of methylated $\mathrm{CpG}$ dinucleotides on the changes in methylation patterns after introducing $\mathrm{SH}-\mathrm{M}$ (9.5-kb insert carrying the $\mathrm{sH} 2 \mathrm{~A}$ and sH2B genes), TH-M (12.6-kb insert carrying the TH2A and TH2B genes), and 25 (a plasmid carrying the mouse MT-I gene and SV40 DNA) constructs into F9 embryonal carcinoma cells, which are known to methylate or demethylate certain types of the viral or transfected DNAs de novo (13, 57).

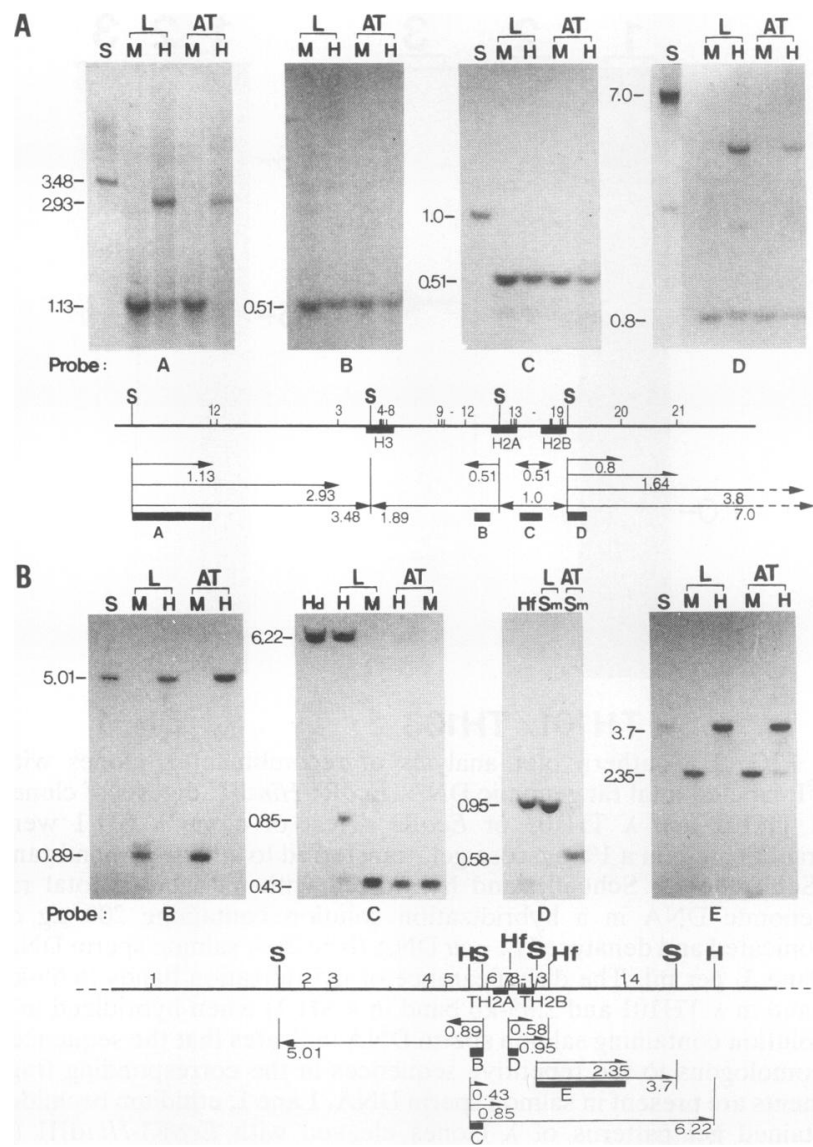

FIG. 4. Methylation patterns of histone genes in adult rat tissues. Methylation patterns of somatic (A) and testis-specific (B) histone genes. Genomic DNAs (10 $\mu \mathrm{g}$ of each) isolated from liver (L) and adult testis (AT) tissues were digested with SacI (S), HindIII (Hd), or Hinfl (Hf) and then MspI (M), HpaII (H), or SmaI (Sm). In all blots except those hybridized with probes C and D (B), genomic DNA was digested first with SacI and then with MspI or HpaII. The first lane at the left of each panel, except for that containing probe $B$ (A), included liver DNA digested with the first enzyme, SacI, HindIII, or HinfI. Both MspI and HpaII recognize CCGG, but HpaII cannot cut when the internal cytosine is methylated. SmaI is also sensitive to DNA methylation. Therefore, the appearance of a high-molecular-weight band in the HpaII or SmaI lanes indicates hypermethylation. DNA samples were fractionated on a $1 \%$ agarose gel, transferred to nylon filters, and hybridized with the ${ }^{32} \mathrm{P}$-labeled probe indicated below each panel. The methylation of MspI site 1 in the flanking sequences of the TH2A and TH2B genes was determined by using probe $A$ (data not shown). The lower part of each panel shows the various restriction fragments detected by the corresponding probes. Molecular sizes (in kilobases) of significant hybridization bands are shown to the left of each panel. Minor bands on a blot probed with fragment $A$ of the somatic histone cluster may be due to cross-hybridization of probe A, containing the LTRs of endogenous retrovirus-like RAL sequences, with other members of the family (44).

To examine the effects of copy number on the demethylation of the $\mathrm{CpG}$ islands located in the bodies of histone genes and at the $5^{\prime}$ end of the mouse MT-I gene, we isolated two series of stable cell lines containing a high or low copy number of each construct. To determine the methylation status of MspI sites in the SH-M construct, genomic DNA isolated from stably transfected clones carrying the SH-M 

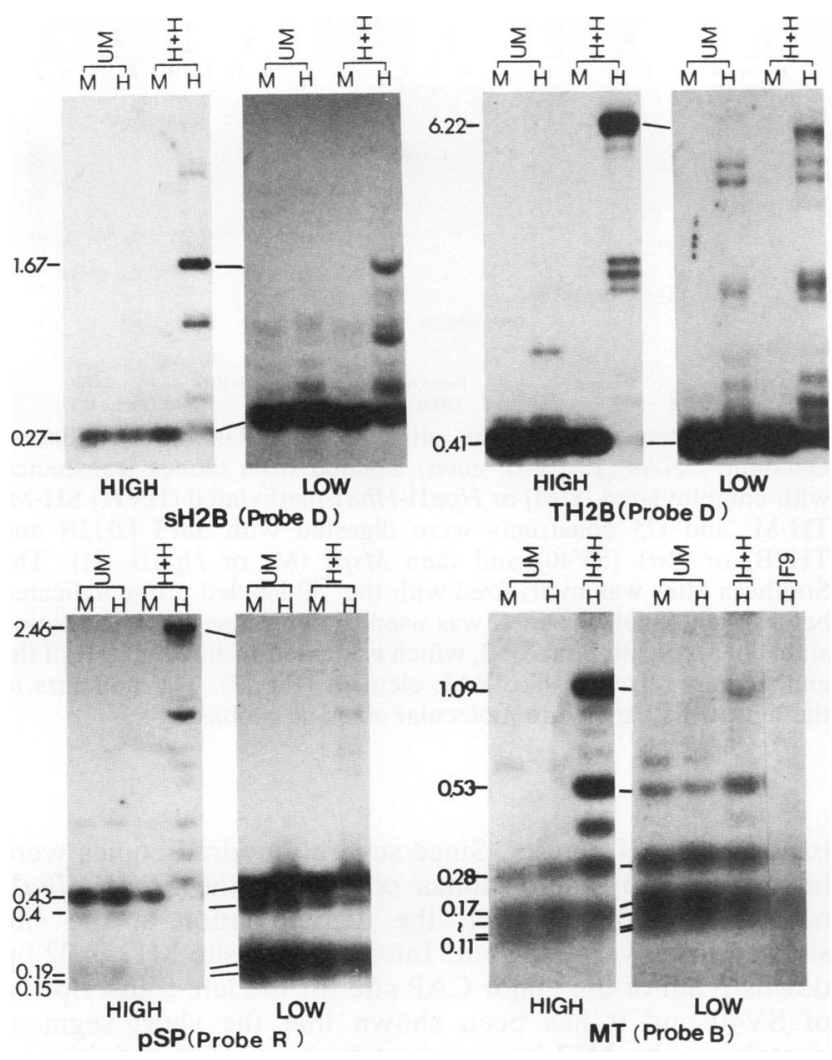

FIG. 5. Effect of the number of integrated copies on demethylation of SH-M, TH-M, and 25 constructs in F9 cells. One or $10 \mu \mathrm{g}$ of genomic DNAs isolated from stably transfected clones containing high or low numbers of integrated copies of the SH-M, TH-M, and t25 constructs were digested first with EcoRI (sH2B), HindIII (TH2B and pSP), or KpnI-PstI (MT) and then with MspI (M) or HpaII (H). Restriction digests were fractionated on a $1 \%$ agarose gel, transferred to nytran membranes, and hybridized with the ${ }^{32}$ P-labeled probe indicated below each panel. The blot for methylation analysis of the TH-M construct was first hybridized with probe $\mathrm{D}$ and then, after autoradiographic exposure and dehybridization, rehybridized with probe $R$ to assess the methylation status of sites in pSP72 vector sequences. Probe $\mathrm{R}$ was a 1-kb DraI-EcoRI fragment isolated from plasmid pSP72. The restriction patterns after digestion with the first enzyme indicated that most of the integrated copies remained intact during cell divisions (data not shown). The low numbers of integrated copies, estimated by densitometric scanning, were as follows: unmethylated SH-M, 40 copies per diploid; SH-M methylated with methylases $H p a I I$ and $H h a \mathrm{I}, 12$ copies per diploid; unmethylated TH-M, 20 copies per diploid; TH-M methylated with methylases $H p a I I$ and $H h a \mathrm{I}, 8$ copies per diploid; unmethylated $\mathrm{t} 25$, 50 copies per diploid; $\mathbf{t} 25$ methylated with methylases $\mathrm{HpaII}$ and HhaI, 30 copies per diploid. At high numbers, more than several hundred copies were integrated into the genomic DNA of F9 cells. $\mathrm{UM}$, unmethylated; $\mathrm{H}+\mathrm{H}$, methylated with methylases $\mathrm{HpaII}$ and HhaI. The numbers to the left of each panel are molecular sizes in kilobases.

construct was digested with EcoRI-HpaII or EcoRI-MspI and the digestion patterns were analyzed by Southern blot analysis with a $0.2-\mathrm{kb} E c o \mathrm{RI}-S a c \mathrm{I}$ fragment as the probe (Fig. 1, probe D). As can be seen in Fig. 5 (sH2B), the $0.27-\mathrm{kb}$ band in the MspI lanes is absent in the HpaII lane containing DNA isolated from stable clones containing high numbers of integrated copies of the SH-M construct. Instead, we observed a strong hybridization band of $1.67 \mathrm{~kb}$, indicating that MspI site 12 , located $0.4 \mathrm{~kb}$ downstream of the sH2A gene, underwent extensive demethylation in F9 cells, whereas all of the other sites in the CpG islands of the sH2A and $\mathrm{sH} 2 \mathrm{~B}$ genes remained methylated. On the other hand, more than $70 \%$ of the integrated copies became demethylated in the CpG islands of the sH2A and sH2B genes at a low copy number, as evidenced by the appearance of the intense $0.27-\mathrm{kb}$ band in HpaII digests (Fig. 5; sH2B, low).

Since the CpG island of the TH2B gene is normally methylated in somatic tissues, in contrast to the unmethylated CpG island of the sH2B gene, it was interesting to see whether the CpG island of the TH2B gene can be demethylated in F9 cells. Figure 5 (TH2B) reveals that the CpG islands of the TH2A and TH2B genes in the TH-M construct was demethylated at a low copy number, like those in somatic histone genes, although at a slightly lower level ( $~ 50 \%$ of integrated copies). Demethylation of the TH2B gene was also greatly inhibited at an increased copy number, and the similar adverse effect of a high copy number on the extent of demethylation was observed at sites in pSP vector sequences which are $\mathrm{CpG}$ rich and efficiently demethylated at a low copy number (Fig. 5; pSP). Demethylation of both sH2B and TH2B genes appears to be specific for F9 cells, since the genes were not substantially demethylated in differentiated L-M(tk ${ }^{-}$) cells (data not shown).

As a control, we also examined demethylation of the MT-I gene in F9 cells. Figure 5 shows that MspI sites 4 to 9 in the CpG island of the MT-I gene were efficiently demethylated only at a low number of integrated copies, as indicated by strong low-molecular-weight bands ranging between 0.11 and $0.28 \mathrm{~kb}$ in the HpaII lanes (MT). The unmethylation of these sites in the endogenous MT-I gene in F9 genomic DNA is also shown in Fig. 5 (MT, lane F9). It is interesting that the $0.53-\mathrm{kb}$ band was more intense than the other low-molecular-weight bands in HpaII-digested DNA from stable clones containing the t25 construct at a high copy number, indicating that MspI site 4 was more efficiently demethylated than sites M5 to M8. Since both stable transformants containing a high or low copy number of methylated constructs were isolated by transfecting the same source of in vitro-methylated DNA, these results strongly suggest that demethylation of those CpG islands is mediated by a trans-acting factor(s) which can be saturated at a high concentration of methylated substrate DNAs.

Removal of fianking sequences does not afiect demethylation. To examine the effect of flanking sequences on the demethylation of $\mathrm{CpG}$ islands, we introduced the methylated and unmethylated TH-S (2.05-kb insert carrying the testisspecific unmethylated domain of the TH2A and TH2B genes) and SH-S (1.5-kb insert carrying unmethylated domain of the sH2A and sH2B genes) constructs into F9 cells. These constructs are highly $\mathrm{CpG}$ rich because of deletion of almost all CpG-depleted flanking sequences. Figure 6 shows that the CpG islands of the sH2B and TH2B genes were significantly demethylated, as indicated by the strong $0.27-$ and $0.41-\mathrm{kb}$ bands in HpaII digests, respectively. We also transfected the 5-kb EcoRV DNA fragment containing the sH2A and sH2B genes into F9 cells to see whether the plasmid topology can affect the demethylation of CpG island DNA. The results showed that the hybridization pattern obtained with the linear EcoRV fragment was almost identical to that observed when the circular plasmid DNA was transfected into F9 cells (data not shown). These results suggest that the cis-acting sequences and/or certain structural features residing in the $\mathrm{CpG}$ islands of histone genes provide a signal responsible for demethylation in F9 cells. 


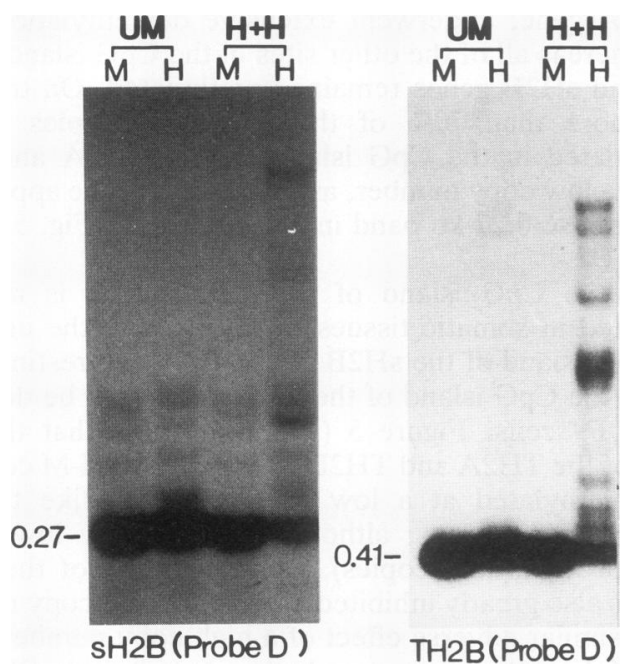

FIG. 6. Efficient demethylation of SH-S and TH-S constructs. Genomic DNAs $(10 \mu \mathrm{g})$ prepared from stably transfected clones carrying low numbers of integrated copies of unmethylated (UM) or HpaII-HhaI-methylated $(\mathrm{H}+\mathrm{H}) \mathrm{SH}-\mathrm{S}$ and TH-S constructs were digested with EcoRI (sH2B) or HindIII (TH2B) and then, after phenol-chloroform extraction and ethanol precipitation, with $M s p I$ (M) or HpaII (H). The Southern filter was then hybridized with the ${ }^{32} \mathrm{P}$-labeled probe indicated below each panel. The integrity of the integrated copies was checked by analyzing the digestion patterns with the first enzyme alone (data not shown in Fig. 6 to 8). The number to the left of each panel is a molecular size in kilobases.

Demethylation in flanking sequences. While the bodies of histone genes and vector sequences are $\mathrm{CpG}$ rich, the flanking sequences, containing mainly repetitive sequences, are $\mathrm{CpG}$ depleted and methylated in both liver and germ cells (Fig. 1). To test the possibility that the flanking sequences are de novo methylated in F9 cells, we examined the methylation status of $\mathbf{M s p I}$ sites in the flanking sequences of SH-M and TH-M constructs. To assess the methylation status of sites M20 and M21 downstream of the sH2B gene, genomic DNAs isolated from stably transfected clones containing the unmethylated or HpaII-HhaI-methylated SH-M constructs at a low copy number were digested with SacIMspI or SacI-HpaII and subjected to Southern blot analysis. As shown in Fig. 7 (sH2B, probe D), site M20 was partially demethylated as judged from the appearance and intensity of the 0.8-kb band in HpaII digests. It is interesting that this site is only partially methylated in rat tissues (Fig. 1A and 4). On the other hand, sites M2 and M3 downstream of the TH2A gene were not demethylated to a significant level (note the strong 3.04-kb band in the HpaII lane of TH2B in Fig. 7). Interestingly, $M s p I$ site 1 in the SH-M construct was efficiently demethylated, even at a high copy number, as indicated by the intense 1.4-kb band in HpaII digests (Fig. 7; sH2B, probe A). Since the site is located not in the CpG island but in the LTR-like RAL element (Fig. 3) and the demethylation of the site is not affected by the increased copy number, it is likely that the mechanism underlying the demethylation of the $M s p$ I site is different from that involved in the demethylation of $\mathrm{CpG}$ island DNAs.

In the $\mathrm{t} 25$ construct, we examined the methylation status of site M12 in the SV40 sequences. As shown in Fig. 7 (SV40), more than $50 \%$ of the integrated copies were demethylated at the M12 site, even at a high copy number, as indicated by the appearance of intense 2.39 - and $1.65-\mathrm{kb}$

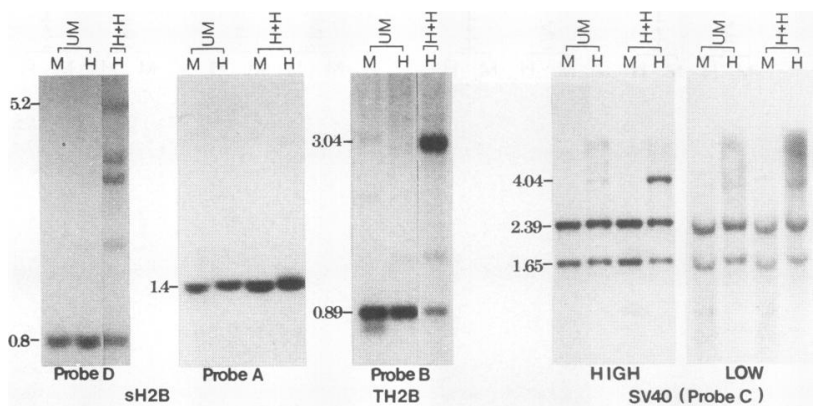

FIG. 7. Demethylation at sites in the flanking sequences. Genomic DNAs (10 $\mu \mathrm{g}$ of each) isolated from clones transfected with unmethylated (UM) or HpaII-HhaI-methylated (H+H) SH-M, TH-M, and t25 constructs were digested with SacI (sH2B and TH2B) or PstI (SV40) and then MspI (M) or HpaII (H). The Southern filter was hybridized with the ${ }^{32} \mathrm{P}$-labeled probe indicated below each panel. Probe A was used to determine the methylation status of MspI site 1 and/or 2, which is located within the LTR of the endogenous retroviruslike RAL element (Fig. 3). The numbers to the left of the panels are molecular sizes in kilobases.

bands in $H p a$ II digests. Since several hundred copies were integrated into stable clones containing the HpaII-HhaImethylated t 25 construct, the demethylation at the site seemed to be very efficient. Interestingly, site M12 is $22 \mathrm{bp}$ downstream of the major CAP site for the late transcription of SV40 and it has been shown that the short segment containing site M12 is important for transcription initiation of the late promoter (2). The efficient demethylation at sites M1 in the SH-M construct, M12 in SV40 sequences, and M4 in the MT-I promoter, as well as the locations of these MspI sites in the promoter or enhancer region, suggest that the same, probably passive, mechanism, which is different from the active mechanism for the demethylation of $\mathrm{CpG}$ islands, is involved in the demethylation of these sequences. We observed no significant de novo methylation in any of the cases tested.

Efiect of mCpG density on demethylation. When DNA is methylated with methylases $H p a I I$ and $H h a I$, only a subset of total methylatable CpG sites can be methylated. Since all CpGs can be the substrates for methyltransferase in vivo, we examined the effect of methylation at all CpGs by methylase SssI on the demethylation in F9 cells. Surprisingly, compared with the efficient demethylation of HpaII-HhaI-methylated constructs, the constructs methylated by methyltransferase Sss I were not demethylated to a significant level in the CpG islands of the sH2A-sH2B, TH2A-TH2B, and MT-I genes, even at a low copy number (Fig. 8). Since 14 of 70 and 20 of $87 \mathrm{CpGs}$ are methylated by methylases HpaII and HhaI in the CpG islands of the TH2A and TH2B and sH2A and sH2B genes, respectively, these results indicate that an about four- to fivefold increase in the number of mCpGs resulted in severe inhibition of demethylation in those CpG islands. Demethylation in vector sequences was also greatly inhibited by increasing the density of mCpGs (data not shown). In contrast, demethylation at sites M1 and M2 (sH2A 3'; note the intense 1.4- and 1.5-kb bands in the HpaII lane of SssI) and M12 (sH2B; note the intense 1.67-kb band in HpaII lanes of SssI) in the SH-M construct was not affected by methylation with methylase SssI, as expected from the locations of these sites in the CpG-depleted sequences (Fig. 8).

The TH2B gene is not active in F9 cells. The demethylation 

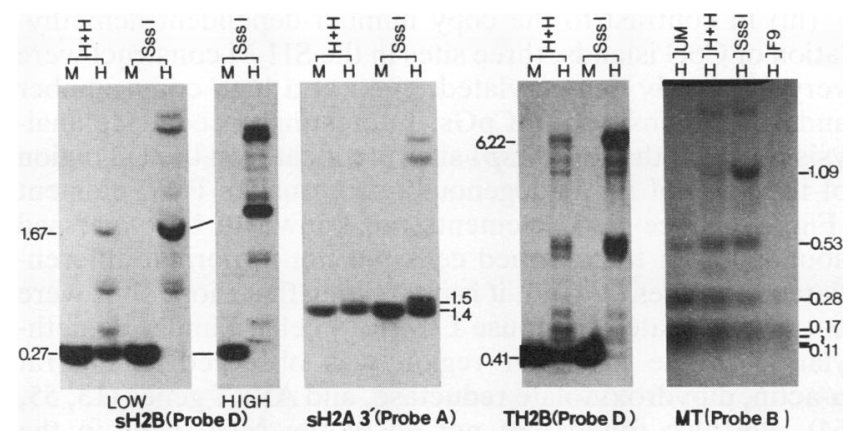

FIG. 8. Demethylation in CpG island DNA is severely inhibited by methylation at every CpG with methylase SssI. Each construct methylated with methylases $\mathrm{HpaII}$ and $\mathrm{HhaI}(\mathrm{H}+\mathrm{H})$ or methylase SssI was stably transfected into F9 cells at a high or low number of integrated copies. Genomic DNAs $(10 \mu \mathrm{g})$ isolated from stably transfected clones were digested with EcoRI (sH2B), SacI (sH2A $3^{\prime}$ ), HindIII (TH2B), or KpnI-PstI (MT) and then digested with either MspI (M) or HpaII (H). The probe used for each Southern filter is indicated below each panel. The low numbers of integrated copies of SssI-methylated constructs (per diploid) were 24 for SH-M, 6 for TH-M, and 24 for t25. At high numbers, more than several hundred copies were integrated into the genomic DNA of F9 cells. The numbers beside the panels are molecular sizes in kilobases.

of the in vitro-methylated TH2A and TH2B genes in F9 cells suggests that the TH2A and TH2B genes are unmethylated at the blastocyst stage during embryonic development. Since DNA methylation appears to be important for transcriptional repression of the TH2B gene in somatic cells (10), it was possible that the TH2B gene might become derepressed in the early embryo stage. To see whether the unmethylated TH2B gene is expressed in F9 embryonic cells, as in other somatic cell lines $(10,24)$, we carried out Northern blot analysis. The stably transfected cells were arrested at the $\mathrm{G}_{1}-\mathrm{S}$ border by treatment with aphidicolin and released from the arrest. Total RNA samples were fractionated on a $1.5 \%$ formaldehyde-agarose gel, transferred to a nylon filter, and hybridized to a ${ }^{32} \mathrm{P}$-labeled probe specific for the TH2B transcript.

Figure 9a shows that the TH2B transcript was not detectable in either arrested (A) or released (R) F9 cells, in contrast to released $\mathrm{C} 3 \mathrm{H} 10 \mathrm{~T} 1 / 2$ cells. The control experiment with an $\mathrm{H} 2 \mathrm{~B}$-specific probe showed that the endogenous copies of the $\mathrm{sH} 2 \mathrm{~B}$ histone gene were efficiently expressed in the $\mathrm{S}$ phase in both cell types (Fig. 9a, sH2B). Since the copy number of the TH2B construct in F9 cells (8 copies) was comparable to that in $\mathrm{C} 3 \mathrm{H} 10 \mathrm{~T} 1 / 2$ cells (12 copies), these results indicate that the TH2B gene is not expressed in F9 cells, although it is expressed in C3H 10T1/2 cells in the $S$ phase. A transient transfection assay further confirmed that the TH2B gene is inactive in F9 cells (data not shown). Since expression of the histone $\mathrm{H}^{2} \mathrm{~B}$ gene is regulated by both $5^{\prime}$ and $3^{\prime}$ sequences, we also introduced plasmid TH2B-CAT into F9 cells to see whether the TH2B promoter is not functional in F9 cells. As shown in Fig. 9b, a very low level of CAT activity was detected for TH2B-CAT in F9 cells in the $S$ phase (F9, lane 5), compared with that in C3H 10T1/2 cells (>50-fold; $10 \mathrm{~T} 1 / 2$, lane 5). These results indicate that the TH2B gene is not functional in F9 embryonic cells, regardless of DNA methylation.
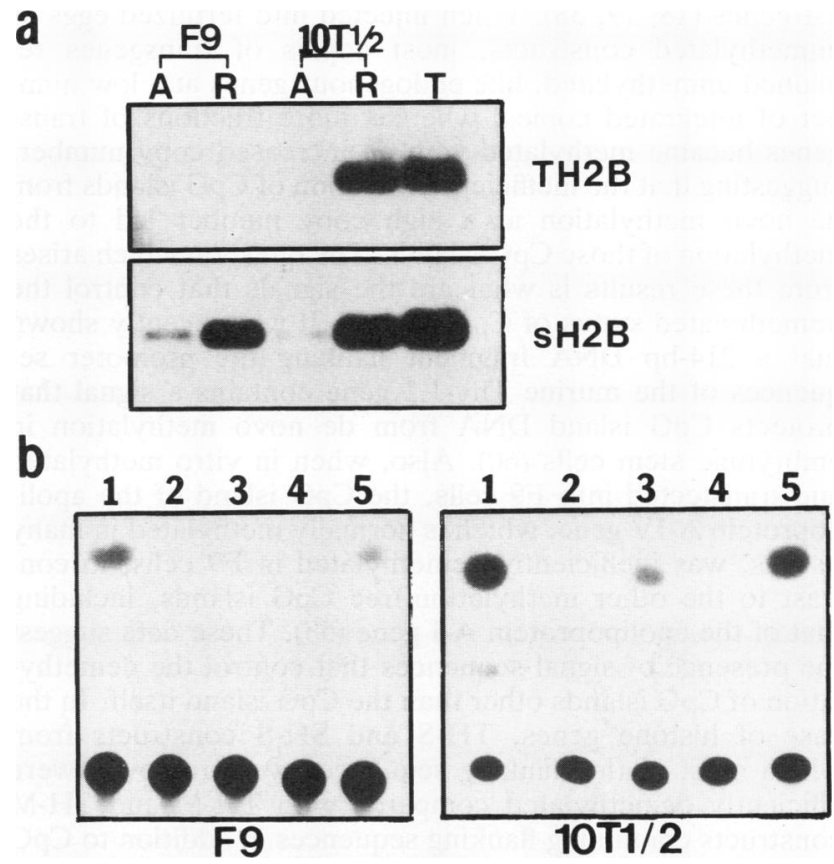

FIG. 9. The TH2B gene is not expressed in F9 cells. (a) Northern analysis of total RNA (15 $\mu \mathrm{g}$ per lane) isolated from stably transfected clones carrying the unmethylated TH-M construct. S-phase cells were harvested at 2 (F9 cells) or 4 (C3H 10T1/2 cells) h after release from the aphidicolin block. Non-S-phase cells were harvested after $20 \mathrm{~h}$ of incubation with aphidicolin. RNA from the testis of a 10-day-old rat was included as a control (lane $\mathrm{T}$ ). The filter was first hybridized with probe TH2B and then, after stripping off of the probe, rehybridized with an $\mathrm{H} 2 \mathrm{~B}$-specific probe as a control to analyze the quality of the RNA samples (sH2B). Lanes: A, RNA from non-S-phase cells; R, RNA from S-phase cells. (b) CAT enzyme activities of TH2B-CAT, the octamer (OM-3) mutant of TH2B-CAT, and plasmid pSV2-CAT. Transfected cells were treated with aphidicolin for $18 \mathrm{~h}$, before cells were harvested at 4 (F9 cells) or 7 (C3H 10T1/2 cells) $h$ after release from the aphidicolin block. Non-S-phase cells were harvested after being treated with aphidicolin for $24 \mathrm{~h}$. After normalization of transfection efficiencies by measuring $\beta$-galactosidase activity, CAT activity was assayed as previously described $(27,28)$. Lanes: 1 , pSV2-CAT; 2 and 3, OM-3; 4 and 5, TH2B-CAT. The odd-numbered lanes show CAT activity in the $S$ phase.

\section{DISCUSSION}

Our analyses of the demethylation of histone genes in F9 cells yielded important insights into the mechanism underlying the demethylation that occurs in embryonic cell lines. (i) The CpG island of the TH2B gene, although exceptionally methylated in adult somatic tissues, was demethylated like those of the sH2B and MT-I genes when methylated with bacterial methyltransferases $\mathrm{HpaII}$ and $\mathrm{HhaI}$ and introduced into F9 cells. The demethylation of those CpG islands is likely to be mediated by a so-called " $\mathrm{CpG}$ island demethylation system" through an active enzymatic mechanism (13), as indicated by the inefficient demethylation at a high number of integrated copies. The lack of substantial demethylation at a high copy number indicates that a saturable factor(s) is involved in the demethylation of $\mathrm{CpG}$ island sequences. A similar effect of copy number on the maintenance of the unmethylated status of CpG island DNA has been observed in transgenic mouse studies on HMGCR-CAT (3-hydroxy-3methylglutaryl coenzyme A reductase) and the murine Thy- 
1.1 genes $(18,19,38)$. When injected into fertilized eggs as unmethylated constructs, most copies of transgenes remained unmethylated, like endogenous genes at a low number of integrated copies, whereas more fractions of transgenes became methylated with an increased copy number, suggesting that the inefficient protection of $\mathrm{CpG}$ islands from de novo methylation at a high copy number led to the methylation of those $\mathrm{CpG}$ islands. The question which arises from these results is what are the signals that control the unmethylated status of $\mathrm{CpG}$ islands. It was recently shown that a 214-bp DNA fragment flanking the promoter sequences of the murine Thy-1.1 gene contains a signal that protects $\mathrm{CpG}$ island DNA from de novo methylation in embryonic stem cells (60). Also, when in vitro methylated and transfected into F9 cells, the CpG island of the apolipoprotein A-IV gene, which is normally methylated in many tissues, was inefficiently demethylated in F9 cells, in contrast to the other methylation-free $\mathrm{CpG}$ islands, including that of the apolipoprotein A-I gene (53). These data suggest the presence of signal sequences that control the demethylation of $\mathrm{CpG}$ islands other than the $\mathrm{CpG}$ island itself. In the case of histone genes, TH-S and SH-S constructs from which most of the flanking sequences were removed were efficiently demethylated compared with TH-M and SH-M constructs containing flanking sequences in addition to $\mathrm{CpG}$ islands, suggesting the possible presence of cis-acting sequences responsible for the demethylation within the $\mathrm{CpG}$ island sequences and/or the possible involvement of certain features of $\mathrm{CpG}$ islands, such as the high density of CpGs, in the demethylation. Transfection experiments with TH-S and SH-S constructs carrying sequential deletions in the $\mathrm{CpG}$ islands of histone genes, as well as competition between different $\mathrm{CpG}$ island sequences, will help to identify the sequence-specific nature of the demethylation system in embryonic cells.

(ii) We also found that the increase in the density of mCpGs in the CpG islands led to severe inhibition of demethylation, even at a low number of integrated copies. One possible explanation is that like the increase in the number of integrated copies, methylation by methylase SssI inhibits demethylation simply by increasing the total number of mCpGs. Alternatively, there may exist a methyl-CpGbinding protein analogous to MeCP1 which binds to CpG islands only when methylated by SssI at a high density, thereby interfering with the demethylation system. Although $\mathrm{MeCP} 1$ and MeCP2 are present at a very low level in F9 cells $(36,37)$, the recent cloning of a novel methyl-CpG-binding protein, $\mathrm{MeCP} 2$, from rat brain tissue suggests the presence of additional methyl-CpG-binding proteins (33). In this regard, it is important to note that MT-I promoter activity was inhibited by methylation with methylase SssI in F9 cells but not by methylation with methylases HpaII and HhaI (32). Thus, both demethylation and transcription were inhibited in F9 cells only with methylation at a high density with methylase SssI. Since the most widely accepted hypothesis explaining transcriptional inhibition by DNA methylation is indirect inhibition by protein mediators such as methyl-CpGbinding proteins $(4,32)$, it is possible that the same mechanism may explain the inhibitory effect of DNA methylation on both demethylation and transcription in F9 cells. Whatever the mechanism that underlies the inhibition of demethylation is, it must be pointed out that all CpGs are potential substrates for de novo methylase activity in vivo. Therefore, any failure to protect $\mathrm{CpG}$ islands from de novo methylation may result in heavily methylated $\mathrm{CpG}$ islands which cannot be rescued by the demethylation system. (iii) In contrast to the copy number-dependent demethylation of $\mathrm{CpG}$ islands, three sites in the SH-M construct were very efficiently demethylated, even at a high copy number and a high density of mCpGs. Interestingly, sequence analysis revealed that two $M s p$ I sites are located in the U3 region of the LTR of the endogenous retroviruslike RAL element (Fig. 3). Since RAL elements are known to be expressed abundantly in transformed cells but not in normal differentiated cell types $(44,59)$, it is interesting that those sites were not demethylated in mouse $\mathrm{L}-\mathrm{M}\left(\mathrm{tk}^{-}\right)$cells. Similar demethylation in the promoter region was observed in the rat $\alpha$-actin, dihydroxyfolate reductase, and APRT genes $(13,55$, 64). We also found that not all of the MspI sites in the promoter of the MT-I gene were demethylated with equal efficiency. Thus, MspI site 4 in MREa (a metal-responsive element) was more efficiently demethylated than other sites in the promoter (58). Since all other sites in the CpG island of the MT-I gene were efficiently demethylated at a low copy number, the difference could be detected only at a high copy number. An HpaII site in SV40 DNA which was efficiently demethylated in F9 cells and was demethylated in two of three integrated copies in rat embryo fibroblast 52.2 cells (17) is located $22 \mathrm{bp}$ downstream of the major initiation site of late transcription. Transfection experiments with linkerscanning mutants revealed that a segment spanning from 20 to $36 \mathrm{bp}$ downstream of the cap site is important for efficient initiation of transcription (2). Taken together, these results point to the possible involvement of the binding of transcription factors in the demethylation in F9 cells. It appears that the demethylation at those sites might take place through a passive mechanism which involves the inhibition of maintenance methylase activity by competitive binding of protein factors to those sites in the hemimethylated intermediate during DNA replication. It has been recently reported that there is a correlation between promoter methylation and gene inactivity for endogenous retroviruslike repetitive sequences such as intracisternal A particles $(11,12)$ and the RAL element (44), Moloney murine leukemia virus (22), the human immunodeficiency virus LTR (3), and adenovirus (28, 30 ). In the human immunodeficiency virus LTR and the late E2A promoter of adenovirus type 2, methylation-mediated transcriptional inhibition was overcome by the presence of the trans-activator Tat and the E1A protein of adenovirus type 2 without promoter demethylation $(3,62)$. The U3 sequence of retroviral sequences is known to contain enhancer sequences (29). Sequence analysis of the RAL element revealed that the sequences homologous to an enhancer core motif (GTGG[T/A][T/A][T/A]) are located immediately adjacent to MspI sites 1 and 2 in U3 (61) (Fig. $3)$. Therefore, it appears to be important to determine the relationship between the binding of protein factors to those MspI sites in U3, demethylation, and activation of the LTR.

(iv) Embryonic carcinoma or stem cells are known to possess de novo methyltransferase activity, as shown by the methylation of proviral sequences (57), the $\beta$-globin gene (8), the collagen IV gene (6), the steroid 21-hydroxylase (C21) gene (60), and flanking sequences of the APRT gene (13) when introduced into embryonic cells. However, we observed no significant methylation of $\mathrm{sH} 2 \mathrm{~B}$ and $\mathrm{TH} 2 \mathrm{~B}$ constructs at any of the sites analyzed in F9 cells. A similar absence of de novo methylation in F9 cells has been reported from the methylation analysis of five different CAT fusion plasmids stably transfected into F9 cells (21). Of the five plasmids tested, only pAFP7000-CAT, containing the 6.7-kb upstream region of the rat $\alpha$-fetoprotein gene, was strongly methylated in F9 cells, suggesting the presence of signals 
that recognize de novo methylase activity. The lack of de novo methylation in many sequences may be in agreement with the low methylase protein level and activity (41) and the low level of global methylation in blastocysts (42). Extensive studies on the methylation patterns of unique gene sequences in the early embryo stage indicated that all of the sites examined are not methylated in the blastocyst stage (25). Therefore, on the basis of these data, the low level of de novo methylation of transfected genes in embryonic cells is not unexpected. The de novo methylation of only certain genes in F9 cells may be explained by the sequence-specific nature of de novo methylase or the presence of more than one methyltransferase in embryonic cells. The recently identified cisacting sequence responsible for de novo methylation of the upstream region of the mouse APRT gene in embryonal carcinoma stem cells may provide an example showing the sequence-specific nature of de novo methylation events (43).

(v) Recent studies on the changes in methylation patterns during embryogenesis indicate that establishment of adult methylation patterns involves erasure of the germ cell-specific methylation patterns at the 8- to 16-cell stages by demethylation, followed by formation of the basic methylation patterns by de novo methylation of non-CpG island sites during gastrulation $(25,42)$. According to this model, it is not surprising that the TH2B gene, like the sH2B gene, was demethylated in F9 embryonal carcinoma cells which were derived from blastocysts. Although demethylation of non-CpG island sequences at the blastula stage suggests partial derepression of many genes in early embryonic cells, as suggested by a transient activation of several genes, including the MyoD gene at the midblastula transition in Xenopus laevis $(48,63)$, the TH2B gene was not active in F9 cells. It is possible that the genes whose expression could be toxic to embryonic cells should be repressed by a mechanism which may be unique to embryonic cells without employing DNA methylation, as suggested by the low level of DNA methylation (42) and methyl-CpG-binding proteins in embryonic cells $(36,37)$.

The unusual methylation of the CpG islands of the TH2A and TH2B genes in somatic tissues may occur later during the gastrulation stage, whereas the TH2A and TH2B genes remain unmethylated in germ cell lines. Since the $\mathrm{CpG}$ islands of the TH2A and TH2B genes were demethylated like other $\mathrm{CpG}$ island sequences in embryonic cells, it is possible that the methylation of the $\mathrm{TH} 2 \mathrm{~A}$ and $\mathrm{TH} 2 \mathrm{~B}$ genes is dominant over the mechanism underlying the protection of CpG island DNAs, including the sH2A and sH2B genes, from the extensive methylation of genomic DNA at the postblastula stage. One possibility is the presence of the signal responsible for de novo methylation, such as a cisacting sequence identified in the upstream region of the mouse APRT gene (43), in the flanking sequences of the TH2A and TH2B genes outside the 13-kb region analyzed in this study. Identification of the signal that controls the unusual methylation of the CpG islands of the TH2A and TH2B genes will provide important insights into the mechanism that underlies the establishment of methylation patterns during embryonic development.

\section{ACKNOWLEDGMENTS}

We thank Inhwan Hwang, Kyu Lim, and Kihong Yoon for helpful discussions. We also thank Byungdon Han for assistance with computer analysis. Aphidicolin was provided by the National Products Branch, National Cancer Institute.

This work was supported by Public Health Service grant HD20136 from the National Institute of Child Health and Human Development.

\section{REFERENCES}

1. Antequera, F., J. Boyes, and A. Bird. 1990. High levels of de novo methylation and altered chromatin structure at CpG islands in cell lines. Cell 62:503-514.

2. Ayer, D. E., and W. S. Dynan. 1988. Simian virus 40 major late promoter: a novel tripartite structure that includes intragenic sequences. Mol. Cell. Biol. 8:2021-2033.

3. Bednarik, D. P., J. A. Cook, and P. M. Pitha. 1990. Inactivation of the HIV LTR by DNA CpG methylation: evidence for a role in latency. EMBO J. 9:1157-1164.

4. Bird, A. 1992. The essentials of DNA methylation. Cell 70:5-8.

5. Bird, A. P. 1986. CpG-rich islands and the function of DNA methylation. Nature (London) 321:209-213.

6. Burbelo, P. D., S. Horikoshi, and Y. Yamada. 1990. DNA methylation and collagen IV gene expression in F9 teratocarcinoma cells. J. Biol. Chem. 265:4839-4843.

7. Cedar, H. 1988. DNA methylation and gene activity. Cell 53:3-4.

8. Cedar, H., R. Stein, Y. Gruenbaum, T. Naveh-Many, N. SciakyGallili, and A. Razin. 1982. Effect of DNA methylation on gene expression. Cold Spring Harbor Symp. Quant. Biol. 47:605-609.

9. Choi, Y.-C. 1992. Ph.D. thesis. University of North Carolina at Chapel Hill.

10. Choi, Y.-C., and C.-B. Chae. 1991. DNA hypomethylation and germ cell-specific expression of testis-specific H2B histone gene. J. Biol. Chem. 266:20504-20511.

11. Falzon, M., and E. L. Kuf. 1991. Binding of the transcription factor EBP-80 mediates the methylation response of an intracisternal A-particle long terminal repeat promoter. Mol. Cell. Biol. 11:117-125.

12. Feenstra, A., J. Fewell, K. Lueders, and E. Kuff. 1986. In vitro methylation inhibits the promoter activity of a cloned intracisternal A-particle LTR. Nucleic Acids Res. 14:4343-4352.

13. Frank, D., I. Keshet, M. Shani, A. Levine, A. Razin, and H. Cedar. 1991. Demethylation of CpG islands in embryonic cells. Nature (London) 351:239-241.

14. Gardiner-Garden, M., and M. Frommer. 1987. CpG islands in vertebrate genomes. J. Mol. Biol. 196:261-282.

15. Gorman, C. 1985. High efficiency gene transfer into mammalian cells, p. 143-190. In D. M. Glover (ed.), DNA cloning: a practical approach, vol. 2. IRL Press, Washington, D.C.

16. Gorman, C. M., L. F. Moffat, and B. H. Howard. 1982. Recombinant genomes which express chloramphenicol acetyltransferase in mammalian cells. Mol. Cell. Biol. 2:1044-1051.

17. Graessmann, M., A. Graessmann, H. Wagner, E. Werner, and D. Simon. 1983. Complete DNA methylation does not prevent polyoma and simian virus 40 virus early gene expression. Proc. Natl. Acad. Sci. USA 80:6470-6474.

18. Gundersen, G., A.-B. Kolstø, F. Larsen, and H. Prydz. 1992. Tissue-specific methylation of a CpG island in transgenic mice. Gene 113:207-214.

19. Gundersen, G., A.-B. Kolstø, and H. Prydz. 1991. Differential methylation of a CpG-island concatemer in hemi- and homozygous transgenic mice. FEBS Lett. 295:214-218.

20. Hamer, D. H., and M. J. Walling. 1982. Regulation in vivo of a cloned mammalian gene: cadmium induces the transcription of a mouse metallothionein gene in SV40 vectors. J. Mol. Appl. Genet. 1:273-288.

21. Hasse, A., W. A. Schulz, and H. Sies. 1992. De novo methylation of transfected CAT gene plasmid constructs in F9 mouse embryonal carcinoma cells. Biochim. Biophys. Acta 1131:16-22.

22. Hoeben, R. C., A. A. J. Migchielsen, R. C. M. van der Jagt, H. van Ormondt, and A. J. van der Eb. 1991. Inactivation of the Moloney murine leukemia virus long terminal repeat in murine fibroblast cell lines is associated with methylation and dependent on its chromosomal position. J. Virol. 65:904-912.

23. Howlett, S. K., and W. Reik. 1991. Methylation levels of maternal and paternal genomes during preimplantation development. Development 113:119-127.

24. Hwang, I., K. Lim, and C.-B. Chae. 1990. Characterization of the S-phase-specific transcription regulatory elements in a DNA replication-independent testis-specific H2B (TH2B) histone gene. Mol. Cell. Biol. 10:585-592.

25. Kafri, T., M. Ariel, M. Brandeis, R. Shemer, L. Urven, J. 
McCarrey, H. Cedar, and A. Razin. 1992. Developmental pattern of gene-specific DNA methylation in the mouse embryo and germ line. Genes Dev. 6:705-714.

26. Kim, Y.-J., I. Hwang, L. L. Tres, A. L. Kierszenbaum, and C.-B. Chae. 1987. Molecular cloning and differential expression of somatic and testis-specific H2B histone genes during rat spermatogenesis. Dev. Biol. 124:23-34.

27. Krayev, A. S., T. V. Markusheva, D. A. Kramerov, A. P. Ryskov, K. G. Skryabin, A. A. Bayev, and G. P. Georgiev. 1982. Ubiquitous transposon-like repeats $B 1$ and $B 2$ of the mouse genome: B2 sequencing. Nucleic Acids Res. 10:7461-7475.

28. Kruczek, I., and W. Doerfler. 1983. Expression of the chloramphenicol acetyltransferase gene in mammalian cells under the control of adenovirus type 12 promoters: effect of promoter methylation on gene expression. Proc. Natl. Acad. Sci. USA 80:7586-7590.

29. Laimins, L. A., P. Gruss, R. Pozzatti, and G. Khoury. 1984. Characterization of enhancer elements in the long terminal repeat of Moloney murine sarcoma virus. J. Virol. 49:183-189.

30. Langner, K.-D., U. Weyer, and W. Doerfler. 1986. trans effect of the E1 region of adenoviruses on the expression of a prokaryotic

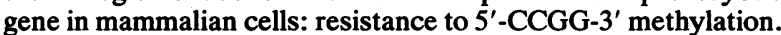
Proc. Natl. Acad. Sci. USA 83:1598-1602.

31. Larsen, F., G. Gundersen, R. Lopez, and H. Prydz. 1992. CpG islands as gene markers in the human genome. Genomics 13:1095-1107.

32. Levine, A., G. L. Cantoni, and A. Razin. 1991. Inhibition of promoter activity by methylation: possible involvement of protein mediators. Proc. Natl. Acad. Sci. USA 88:6515-6518.

33. Lewis, J. D., R. R. Meehan, W. J. Henzel, I. Maurer-Fogy, P. Jeppesen, F. Klein, and A. Bird. 1992. Purification, sequence, and cellular localization of a novel chromosomal protein that binds to methylated DNA. Cell 69:905-914.

34. Li, E., T. H. Bestor, and R. Jaenisch. 1992. Targeted mutation of the DNA methyltransferase gene results in embryonic lethality. Cell 69:915-926.

35. Lock, L. F., N. Takagi, and G. R. Martin. 1987. Methylation of the Hprt gene on the inactive $\mathrm{X}$ occurs after chromosome inactivation. Cell 48:39-46.

36. Meehan, R. R., J. D. Lewis, and A. P. Bird. 1992. Characterization of MeCP2, a vertebrate DNA binding protein with affinity for methylated DNA. Nucleic Acids Res. 20:5085-5092.

37. Meehan, R. R., J. D. Lewis, S. McKay, E. L. Kleiner, and A. P. Bird. 1989. Identification of a mammalian protein that binds specifically to DNA containing methylated CpGs. Cell 58:499-507.

38. Mehtali, M., M. LeMeur, and R. Lathe. 1990 . The methylationfree status of a housekeeping transgene is lost at high copy number. Gene 91:179-184.

39. Milner, R. J., F. E. Bloom, C. Lai, R. A. Lerner, and J. G. Sutcliffe. 1984. Brain-specific genes have identifier sequences in their introns. Proc. Natl. Acad. Sci. USA 81:713-717.

40. Monk, M. 1986. Methylation and the X chromosome. BioEssays 4:204-208.

41. Monk, M., R. L. P. Adams, and A. Rinaldi. 1991. Decrease in DNA methylase activity during preimplantation development in the mouse. Development 112:189-192.

42. Monk, M., M. Boubelik, and S. Lehnert. 1987. Temporal and regional changes in DNA methylation in the embryonic, extraembryonic and germ cell lineages during mouse embryo development. Development 99:371-382.

43. Mummaneni, P., P. L. Bishop, and M. S. Turker. 1993. A cis-acting element accounts for a conserved methylation pattern upstream of the mouse adenine phosphoribosyltransferase gene. J. Biol. Chem. 268:552-558.

44. Nakamuta, M., M. Furuich, K. Takahashi, N. Suzuki, H. Endo, and M. Yamamoto. 1989. Isolation and characterization of a family of rat endogenous retroviral sequences. Virus Genes 3:69-83.

45. O'Connell, C. D., and M. Cohen. 1984. The long terminal repeat sequences of a novel human endogenous retrovirus. Science 226:1204-1206.
46. Pfeifer, G. P., S. D. Steigerwald, R. S. Hansen, S. M. Gartler, and A. D. Riggs. 1990. Polymerase chain reaction-aided genomic sequencing of an X chromosome-linked CpG island: methylation patterns suggest clonal inheritance, CpG site autonomy, and an explanation of activity state stability. Proc. Natl. Acad. Sci. USA 87:8252-8256.

47. Riggs, A. D., and G. P. Pfeifer. 1992. X-chromosome inactivation and cell memory. Trends Genet. 8:169-174.

48. Rupp, R. A. W., and H. Weintraub. 1991. Ubiquitous MyoD transcription at the midblastula transition precedes inductiondependent MyoD expression in presumptive mesoderm of $\mathrm{X}$. laevis. Cell 65:927-937.

49. Sanford, J. P., H. J. Clark, V. M. Chapman, and J. Rossant. 1987. Differences in DNA methylation during oogenesis and spermatogenesis and their persistence during early embryogenesis in the mouse. Genes Dev. 1:1039-1046.

50. Sanger, F., S. Nicklen, and A. R. Coulson. 1977. DNA sequencing with chain-terminating inhibitors. Proc. Natl. Acad. Sci. USA 74:5463-5467.

51. Sapienza, C., A. C. Peterson, J. Rossant, and R. Balling. 1987. Degree of methylation of transgenes is dependent on gamete of origin. Nature (London) 328:251-254.

52. Sasaki, H., T. Hamada, T. Ueda, R. Seki, T. Higashinakagawa, and Y. Sasaki. 1991. Inherited type of allelic methylation variations in a mouse chromosome region where an integrated transgene shows methylation imprinting. Development 111:573-581.

53. Shemer, R., S. Eisenberg, J. L. Breslow, and A. Razin. 1991. Methylation patterns of the human ApoA-I/C-III/A-IV gene cluster in adult and embryonic tissues suggest dynamic changes in methylation during development. J. Biol. Chem. 266:23676-23681.

54. Shemer, R., T. Kafri, A. O'Connell, S. Eisenberg, J. L. Breslow, and A. Razin. 1991. Methylation changes in the apolipoprotein AI gene during embryonic development of the mouse. Proc. Natl. Acad. Sci. USA 88:11300-11304.

55. Shimada, T., K. Inokuchi, and A. W. Nienhuis. 1987. Sitespecific demethylation and normal chromatin structure of the human dihydrofolate reductase gene promoter after transfection into CHO cells. Mol. Cell. Biol. 7:2830-2837.

56. Singer-Sam, J., M. Grant, J. M. LeBon, K. Okuyama, V. Chapman, M. Monk, and A. D. Riggs. 1990. Use of a HpaIIpolymerase chain reaction assay to study DNA methylation in the Pgk-1 CpG island of mouse embryos at the time of X-chromosome inactivation. Mol. Cell. Biol. 10:4987-4989.

57. Stewart, C. L., H. Stuhlmann, D. Jähner, and R. Jaenisch. 1982. De novo methylation, expression, and infectivity of retrovira genomes introduced into embryonal carcinoma cells. Proc. Natl. Acad. Sci. USA 79:4098-4102.

58. Stuart, G. W., P. F. Searle, and R. D. Palmiter. 1985. Identification of multiple metal regulatory elements in mouse metallothionein-I promoter by assaying synthetic sequences. Nature (London) 317:828-831.

59. Suzuki, N., T. Fujiyoshi, Y. Maehara, K. Takahashi, M. Yamamoto, and H. Endo. 1986. A new family of LTR-like sequences abundantly expressed in rat tumors. Nucleic Acids Res. 14:9271-9289.

60. Szyf, M., G. Tanigawa, and P. L. McCarthy. 1990. A DNA signal from the Thy-1 gene defines de vovo methylation patterns in embryonic stem cells. Mol. Cell. Biol. 10:4396-4400.

61. Weiher, H., M. König, and P. Gruss. 1983. Multiple point mutations affecting the simian virus 40 enhancer. Science 219: 626-631.

62. Weisshaar, B., K.-D. Langner, R. Jüttermann, U. Müller, C. Zock, T. Klimkait, and W. Doerfler. 1988. Reactivation of the methylation-inactivated late E2A promoter of adenovirus type 2 by E1A (13 S) functions. J. Mol. Biol. 202:255-270.

63. Wolffe, A. P., and D. D. Brown. 1988. Developmental regulation of two 5S ribosomal RNA genes. Science 241:1626-1632.

64. Yisraeli, J., R. S. Adelstein, D. Melloul, U. Nudel, D. Yaffe; and H. Cedar. 1986. Muscle-specific activation of a methylated chimeric actin gene. Cell 46:409-416. 